\title{
MEDICAL PLANT OF ALOE VERA IN DESERT REGIONS OF IRAN: GREENHOUSES, ECONOMIC IMPORTANCE, DEVELOPMENT, EXTENSION, PROCESSING AND MARKETING
}

\author{
Farhood GOLMOHAMMADI ${ }^{*}$
}

\author{
${ }^{1}$ Department of Agricultural Economics and Extension, Islamic Azad University- Birjand Branch - Birjand. Iran
}

\begin{abstract}
Medical plants are the best source for getting treatment from various diseases. Using of natural substances with therapeutic properties has been used since ancient times. More than 500 species of Aloe Vera are known. This plant is native to tropical areas, including the north of Africa, Europe and the southern part of the Mediterranean region. Aloe Vera grows widely in the south of Iran and is cultured for the pharmaceutical uses. Aloe Vera is a plant with structural and physiological adaptations that allow it to survive in arid or semiarid regions with erratic rainfall. Aloe Vera is a medicinal plant cultivated for various applications in medical, food and health products. Aloe Vera has been used for centuries for its health, beauty, medicinal and skin care properties. Aloe Vera is a plant that can produce sap and gel. The gel is extracted from the leaves, and this is the most widely used substance as a treatment. Different from traditional treatment modalities, Aloe Vera will great reduce medical cost intended as complementary therapy. Aloe Vera is much more effective and less costly in the prevention and healing the ulcers compared to current treatments. Also, since the revival of traditional medicine is important and the side effects of this drug has been proven to be trivial over the years, it seems Aloe Vera is a good substitute to replace the current methods or to be used as a complementary method for prevention of pressure ulcers and improving community health. In this article, introducing various aspects of cultivating Aloe Vera greenhouses in desert regions of Iran and their economic importance plus approaches for their development, extension, processing and marketing. Main locations of study were greenhouses of Aloe Vera in two provinces in Iran, namely South Khorasan and Semnan provinces in the east and north of the country. For doing this study utilized qualitative approach with its main tools for gathering information such as participatory observation, maps, scientific articles, pictures, documents etc.. In the end present appropriate approaches for improving its economic importance, development, extension, processing and marketing in Iran.
\end{abstract}

Keywords: Aloe Vera, Greenhouses, Desert regions, South Khorasan province, Iran

*Corresponding author: Department of Agricultural Economics and Extension, Islamic Azad University- Birjand Branch - Birjand. Iran E mail: farhood.gol@gmail.com (F. GOLMOHAMMADI)

$\begin{array}{llll}\text { Farhood GOLMOHAMMADI } & \text { (iD) https://orcid.org/0000-0003-0939-4678 } & \text { Received: May 31, 2021 }\end{array}$

Accepted: October 06, 2021

Published: January 01, 2022

Cite as: Golmohammadi F. 2022. Medical plant of Aloe Vera in desert regions of Iran: greenhouses, economic importance, development, extension, processing and marketing. BSJ Agri, 5(1): 1-15.

\section{Introduction}

Medical plants are the best source for getting treatment from various diseases. Using of natural substances with therapeutic properties has been used since ancient times. Aloe Vera is a medical which has many benefits that is used in medicine to several problems in the health of human body. Aloe Vera is a plant that can produce sap and gel. The gel is extracted from the leaves, and this is the most widely used substance as a treatment (Rozani and Kusbaryanto, 2019). Aloe Vera is one of the few succulent plants that throughout history has maintained an important place in the pharmacopoeias of various cultures of the world. It was used by the ancient Egyptians in mummification rituals, and in China and India, it has been applied in traditional medicine since 400 BC. Dioscorides mentions its use for the treatment of almost all ailments, from insomnia to itching of the eyes (Imery-Buiz, 2012). Aloe Vera is a medicinal plant cultivated for various applications in medical, food and health products (Singh et al., 2021).

Aloe Vera is an herbaceous and perennial plant that belongs to the Liliaceae family and used for many medicinal purposes (Hekmatpou et al., 2019). Aloe barbadensis Miller (Aloe Vera), is a perennial plant of the lily (Liliaceae) or Aloeaceae family, which is a tropical or subtropical plant characterized by lance shaped leaves with jagged edges and sharp points (Safari et al., 2019). Aloe (Aloe Vera L., Liliaceae family) has applications in health and cosmetic products as well as antioxidant, anticancer, anti-inflammatory, laxative, antiatherosclerosis properties. It includes 75 active components that contain vitamins, enzymes, minerals, sugars, Lignin, salicylic acid, and amino acids. Plenty of major components such as: Aloe-emodin, Aloetic-acid, Anthranol, Barbaloin, Mannan and its derivatives, 8-Cglusoly-(2'-Ocinnamoly), -7-0-methlyaloediol A, Alkaline phospha amylase, bradykinase, carboxypeptidase, catalase, cyclooxidase, cyclooxygenase, lipase, oxidase, phosphoenolpyruvate, carboxylase, superoxide 


\section{Black Sea Journal of Agriculture}

dismutase, Calsium, Chlorine, Chromium, Copper, Iron, Magnesium, Arachidonic acid, Y-linolenic acid, steroids, Mannose, glucose, L-rhamnose, Aldopentose, Vitamin A, B12, C, E, choline and folic acid, Auxins and Gibberellins have been found (Alinejad-Mofrad et al., 2015).

Aloe Vera is a stem less or very short-stemmed plant growing to 60-100 centimeters (24-39 inches) tall, spreading by offsets. The leaves are thick and fleshy, green to grey-green, with some varieties showing white flecks on their upper and lower stem surfaces. The margin of the leaf is serrated and has small white teeth. The flowers are produced in summer on a spike up to 90 cm (35 in) tall, each flower being pendulous, with a yellow tubular corolla $2-3 \mathrm{~cm}(3 / 4-11 / 4$ in) long. Like other Aloe species, Aloe Vera forms arbuscular mycorrhiza, a symbiosis that allows the plant better access to mineral nutrients in soil. Aloe Vera leaves contain phytochemicals under study for possible bioactivity, such as acetylated mannans, polymannans, anthraquinone C-glycosides, anthrones, and other anthraquinones, such as emodin and various lectins (Jamshidi et al., 2018). Aloe Vera is a xerophytic plant with structural and physiological adaptations that allow it to survive in arid or semiarid regions with erratic rainfall (Imery-Buiz, 2012).

This plant has triangular leaves. Fleshy with jagged edges, yellow tubular flowers and fruits which contain a lot of seeds. Every leaf consults of 3 clear get which of containing $99 \%$ water and the other are made of glucomannan, amino acid, lipids, sterols, vitamins, and middle lays of latex which of bitter yellow sap and contains anthraquinone, glycosides, and thick out layer of is $15-20$ cells referred to as peel that has a protective function, synthesize carbohyidrates and proteins. Inside the skin is a collection of blood vessels responsible to transport substances such as water (xylem) and starch (phloem). Various Aloe Vera extracts are mate to be easy is used in medicine to humans like gel, oil, juice, and tablets. In several researches in-vitro indicate that Aloe Vera leaves showed contain more than 75 nutrients and 200 active compounds, including 20 minerals, 18 amino acids and 12 vitamins. Also contain the most important components which are needed by the human body. Aloe Vera has vitamins A, B1, B2, B6, B12, C and E. Aloe Vera has a high enzyme content (for about 92 enzyme), which makes it a rare source and valuable because of enzyme help the body absorb basic nutrients at the same time purifying it and used as an antifungal, anti-inflammatory, anti-septic, can be used to accelerate the healing process of wounds. By looking at kinds of treatment using Aloe Vera above, so that was done a deep literature to treatment using Aloe Vera in dealing with health problems. Aloe Vera can also be used as therapy or treatment in melasma patients with fix function skin pigment. Utilization of treatment using Aloe Vera proven to accelerate the process of wound healing and decrease some health problems of pain intensity (Rozani and Kusbaryanto, 2019).
Its therapeutic potential is demonstrated every day in the many laboratories, medical centers, and traditional hospitals that study and evaluate natural healing alternatives for diseases such as cancer, as well as gastrointestinal, skin, cardiovascular, respiratory, and metabolic disorders. Their investigations have found that the administration of A. Vera extracts acts successfully as a treatment to alleviate these conditions, both by itself or as a coadjutant of formal medicine effects. There are currently over $800 \mathrm{~km}^{2}$ cultivated with A. Vera, mainly in dry regions in the Americas, southern Europe, Africa, Arabia, India, China, and Australia; they produce the raw material for the food, pharmaceutical, and cosmetics industries. Agricultural and industrial activities based on A. Vera have a projected annual growth of nearly $8 \%$ with an overall market of about US $\$ 200$ billion. However, low genetic variability and the emergence of phytosanitary problems threaten crop productivity, generating the need to better understand ecological and agronomic aspects of this species and to search for new cultivars. Several research centers worldwide have oriented their efforts in this direction, carrying out basic studies in genetics, biotechnology, physiology, ecology, reproductive biology, plant pathology, entomology, and other scientific disciplines in order to obtain pathogentolerant experimental genotypes together with increases in crop yield, efficiency, and quality (Imery-Buiz, 2012). Aloe Vera is much more effective and less costly in the prevention and healing the ulcers compared to current treatments. Also, since the revival of traditional medicine is important and the side effects of this drug has been proven to be trivial over the years, it seems Aloe Vera is a good substitute to replace the current methods or to be used as a complementary method for prevention of pressure ulcers and improving community health (Hekmatpou et al., 2018).

The succulence of the leaves is a xerophytic adaptation based on the presence of a specialized tissue (hydro parenchyma) where water is stored in large cells with thin walls. Mucilage contained in this tissue maintains the water status of the plant, due to little variation in its water potential even in drought conditions. A. Vera plants show crassulacean acid metabolism (CAM) and open their stomata at night to convert atmospheric carbon dioxide into malic acid, which they use to perform photosynthesis during the day, when their stomata are closed to prevent loss of moisture. The CAM activity and the accumulation of large quantities of polysaccharides in the leaves are mechanisms of drought resistance and may aid the rehydration of other leaf cells with a lower water potential (Imery-Buiz, 2012).

Aloe, which originated from Africa under dry and hot weather conditions, is currently growing worldwide in tropical and subtropical areas. It is well recognized for its extremely high utilization qualities and its ability to adapt to various environments, making it easy for cultivation in other parts of the world with hot and humid climates (Young In and Hyung, 2006). More than 


\section{Black Sea Journal of Agriculture}

500 species of Aloe Vera are known. This plant is native to tropical areas, including the north of Africa, Europe and the southern part of the Mediterranean region. A Vera grows widely in the south of Iran and is cultured for the pharmaceutical uses (Safari et al., 2019). In this article, introducing various aspects of cultivating Aloe Vera in greenhouses in desert regions of Iran (especially South Khorasan and Semnan provinces in the east and north of the country) plus its open farming in other provinces and their economic importance plus approaches for their development, extension, processing and marketing (Figure 1).

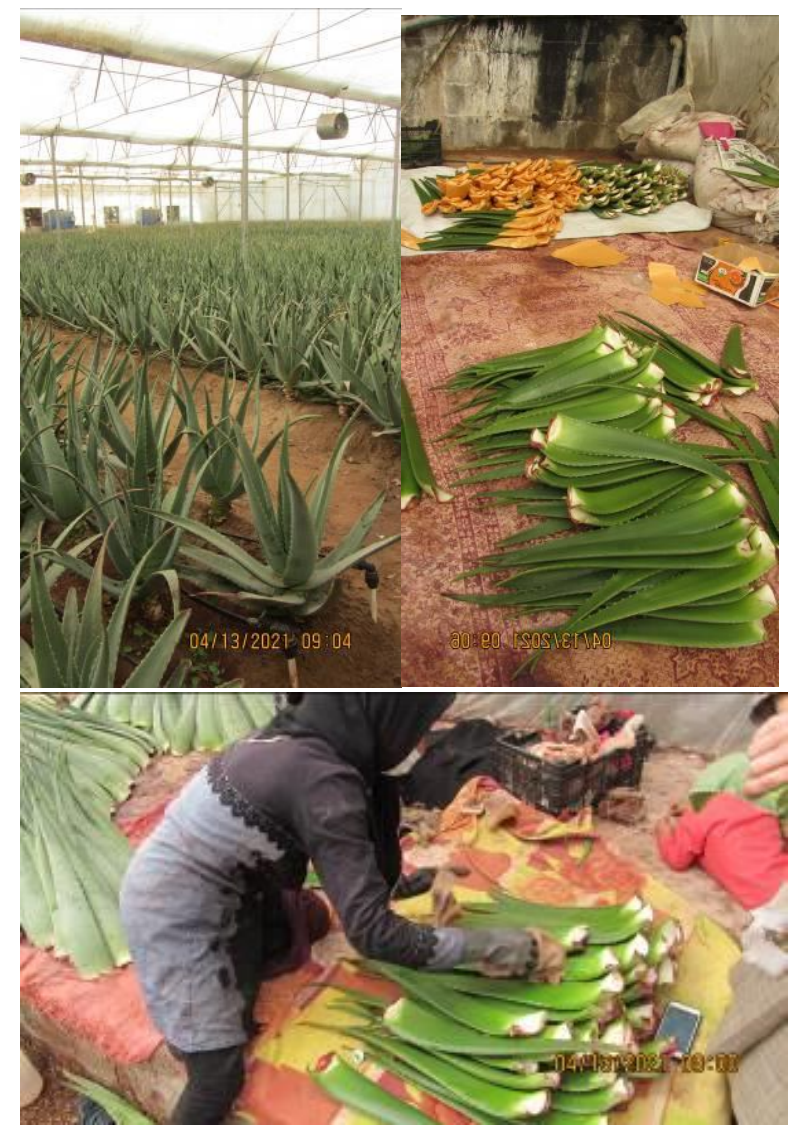

Figure 1. An Aloe Vera greenhouse that belonging to an urban educated woman entrepreneur that has academic degree in agricultural engineering - with $15 \mathrm{~km}$ distance of greenhouse to Birjand, center of South Khorasan Province, east of Iran (By author; Spring, 2021).

\section{Extent and Amount of Aloe Vera Production in Iran}

Cultivating of Aloe Vera for supplying to market in Iran has been begun less than one decade and therefore isn't available a national statistics for its extent and amount of Aloe Vera production in all of the provinces of Iran and in the level of the country. In north provinces of the country such as Guilan and Mazandran provinces and south and west provinces such as Bushehr and Ilam provinces we see dominance cultivating of Aloe Vera in open farms because of availability good conditions such as high degree of humidity and temperature. In these provinces we see also cultivating of Aloe Vera in greenhouses in fewer extent especially by academic agricultural graduated in Iran.

For example, in Bushehr province in south west of Iran and in besides of Seashores of Persian Gulf we see most extent of Aloe Vera farms in open air in 100 ha with annual production 2400 tons of its leaves (Figure 2).

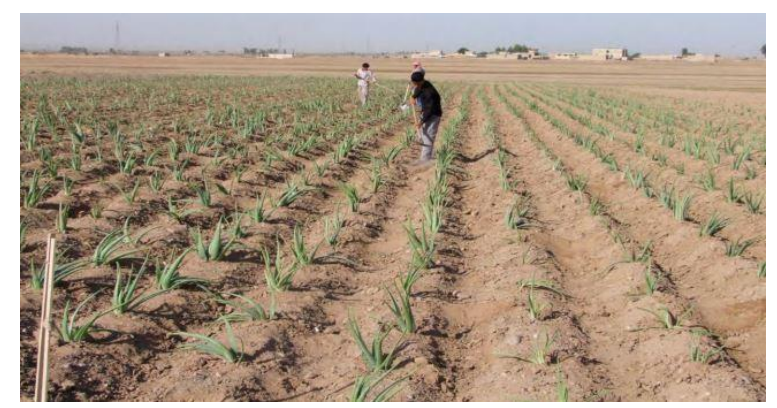

Figure 2. Plantation of Aloe Vera in farm in a village near Ilam city, capital of Ilam province, south west of Iran, and near borders of Iraq, spring 2012. (Noori, 2012).

But in desert provinces such as South Khorasan and Semnan provinces we see cultivating of Aloe Vera in greenhouses in 3.5 and 4 ha exclusively. In these provinces Aloe Vera can't grow in open air farms because of its high sensitivity to below degrees temperatures (under zero centigrade) that cause die of this plant (Table 1).

Table 1. Situation of stakeholders in Aloe Vera greenhouses in South Khorasan and Semnan provinces

\begin{tabular}{lcc}
\hline Items & $\begin{array}{c}\text { South Khorasan } \\
\text { province }\end{array}$ & $\begin{array}{c}\text { Semnan } \\
\text { province }\end{array}$ \\
\hline $\begin{array}{l}\text { Extent of Aloe Vera } \\
\text { greenhouses (ha) }\end{array}$ & 3.5 & 4 \\
$\begin{array}{l}\text { Number of } \\
\text { stakeholders }\end{array}$ & 6 & 10 \\
\hline
\end{tabular}

In Khorasan Razavi province in north east of Iran, there are 22 ha Aloe Vera in greenhouses and less than 2 ha Aloe Vera farms in open air with total 7000 tons annual production of its leaves.

Also greatest and most extensive complex of Aloe Vera in greenhouses is available in Mashhad city center of Khorasan Razavi province in extent of 2 ha that contains 20 Aloe Vera greenhouses and provide employment for 40 persons directly and 120 persons indirectly.

In Delgan city with $478 \mathrm{~km}$ distance to Zahedan city center of Sistan and Baluchestan province in south east of Iran and in besides of Seashores of Oman sea and Indian ocean, 50 ha Aloe Vera farms in open air cultivated first time in 2020 that there aren't precise statistics of their production yet.

In other provinces of Iran Aloe Vera cultivated in open air farms (less) and greenhouses (more) in extent of 1-2 ha with an average production of its leaves $40-60$ tons 


\section{Black Sea Journal of Agriculture}

annually, that there aren't precise statistics on their cultivating extent (Iranian Bureau of Statistics, 2021).

\section{Physical Description}

Aloe Vera is an evergreen, perennial, succulent (cactus like) plant that has gray - green, simple, lance - shaped leaves with a pointed apex (lanceolate). The leaves do not have stalks (petioles). The margins have small grayish teeth. The leaves are arranged alternately to form a rosette above a very short stem. The main rosette reaches approximately 2 feet $(61 \mathrm{~cm})$ in height, and the plant continually produces little offset rosettes. The flowers are regular, bisexual, yellow to orange in color, and appear in terminal series of flowers on lateral stalks (racemes). These flowers produce capsules with many flattened seeds (Figure 3) (Barceloux, 2008).

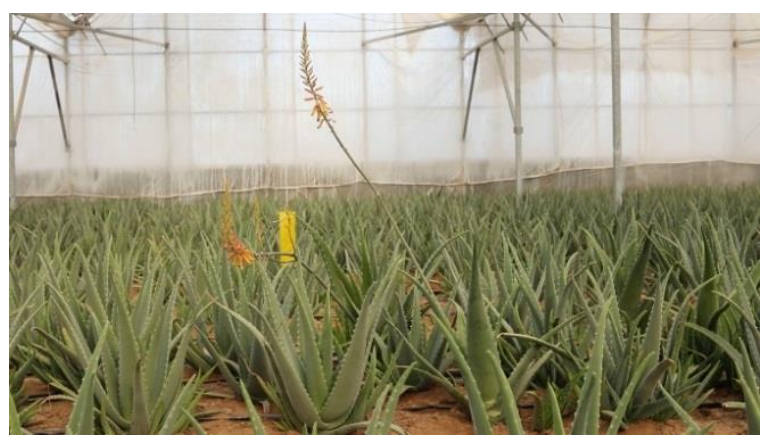

Figure 3. These flowers produce capsules with many flattened seeds. In a greenhouse with $15 \mathrm{Km}$ distance to Birjand, center of South Khorasan Province, east of Iran (By author; Spring, 2021).

\section{Distribution and Ecology}

The overexploitation of natural populations of Aloe Vera for over 3000 years due to their direct use for medicinal purposes, as well as their introduction, cultivation, and marketing in different regions of the world, makes the origin of Aloe Vera uncertain. Aloe Vera can be found anywhere in the world, but its extensive cultivation is limited to tropical and subtropical regions. In the Americas, it is commercially exploited in large plantations in the southern United States, Mexico, the Dominican Republic, Haiti, Puerto Rico, Cuba, the Bahamas, Barbados, Aruba, Bonaire, Curacao, Belize, Guatemala, Costa Rica, Colombia, Venezuela, Ecuador, Brazil, Peru, Bolivia, and down to northern Chile, Argentina, and Paraguay (Imery-Buiz, 2012).

Aloe adapts well to desert climates. This plant is native to Arabia and Madagascar, but the largest distribution occurs in South Africa. In the United States, Aloe Vera grows in the drier parts of Texas, Florida, Puerto Rico, and Hawaii (Barceloux, 2008). Among the various Aloe species used for medical purposes are Socotra aloe (Aloe perryi Baker), which can be found in the African Somalia and Socotra Island region, Cape Aloe (Aloe ferox Miller, Aloe Africana Miller, Aloe spicata Baker), which is found near the African Cape Town region, and Curacao aloe
(Aloe barbadensis Miller), which is found in parts of Mexico, Central America, the Caribbean and most recently Florida and southern Texas. Curacao aloe is better known as Aloe Vera.

These aloe species are currently listed in the pharmacopeia of many countries in forms of plain aloe, extract and/or powder (Young In and Hyung, 2006).

In Aloe Vera pots, the species requires well-drained, sandy potting soil and bright, sunny conditions. Aloe plants can turn red from sunburn under too much direct sun, though gradual acclimation may help. The use of a good-quality commercial propagation mix or packaged "cacti and succulent mix" is recommended, as they allow good drainage (Jamshidi et al., 2018).

\section{Aloe Vera Traditional Medicinal Uses in Various Ancient Cultures}

Aloe Vera has been used for centuries for its health, beauty, medicinal and skin care properties (Sahebnasagh et al., 2020). At present, a number of prescribed drugs come from plants. The medicinal properties and ornamental value of Aloe Vera have been recognized by civilizations throughout the world and are described in ancient documents, including the Bible. Aloe Vera has been used for medical purpose in several cultures for a thousand of years Egypt, India, Mexico, Japan and China. In the old World, it is cultivated throughout the Mediterranean and other dry areas of Spain, Italy, India, South Africa, the Arabian peninsula, China, Malaysia, Japan, Australia, Vietnam, Taiwan, and Nigeria. Aloe Vera is a medicinal plant from 1500 years BC in many countries, including Greece, China, Mexico, which had been traditionally used for centuries as a local medicine for various diseases and skin lesions. The use of Aloe plants as magical and superstitious symbols is widespread throughout the world, especially in Africa and in those places where people of African descent live or where components of their culture have been adopted. In the Caribbean and other American countries, whole Aloe Vera plants are placed above the entrance doors to houses as a warning to people with malicious intent and to keep adversities of all kinds at bay. Some people even put coins at the base of the plants in the hope of economic prosperity for their families (Imery-Buiz, 2012).

Traditional uses of Aloe Vera include the treatment of arthritis, asthma, fungal infections, digestive and bowel disorders (e.g., constipation), lupus erythematous, skin disorders (e.g., seborrheic dermatitis), musculoskeletal injuries, and gastro duodenal ulcers. Other uses include application as an insect repellant and the treatment of diabetes mellitus, antihemorrhoidal agent, gout, tuberculosis, gonorrhea, headaches, and eczema (Barceloux, 2008).

Different from traditional treatment modalities, Aloe Vera will great reduce medical cost intended as complementary therapy (Rozani and Kusbaryanto, 
2019).

Succulent Aloe plants have been used to treat wounds since ancient times and are mentioned in the Ebers papyrus, an important medical text of ancient Egypt, dating from 1550 BCE (Edwards et al., 2015).

Currently there are over 360 known species of aloe and it has been used for medical purposes for probably at least 4000 years. The use of this plant for medical needs has already been revealed by historical records in regions such as ancient Persia and Egypt, Greece, Rome, India, Africa, China, Korea and Japan. Later, with the Spanish discovery of the Americas, aloe completed its spread throughout all inhabited continents of the world. The first record of human use of Aloe is the Sumerian hieroglyphic alphabets engraved on clay tablets during the Mesopotamia civilization circa 2200 BC. According to them the aloe leaves were used as a laxative. Scriptures on the Ebers papyrus that were found inside the tombs of mummies in the Egyptian Tebe region show 12 formulas that used aloe with other ingredients to produce internal medicine or a medicine for external use, further proving the use of the plant. Material Medica, which was written by Hippocrates circa $450 \mathrm{BC}$, did not have any direct indication of aloe, but according to the Indian medication writing called the Copra (which was written during the same era) aloe was used for healing external wounds and constipation. The Greek Herbal written by Dioscoreded circa $41 \mathrm{AD}$ recorded detailed information on the use of Aloe Vera and its extracts for wound healing, treatment of gum diseases and constipation during the Roman expedition. The hemostatic use was also reported when in dried power form. Meanwhile, according to the Chinese 'Geboboncho' written during the Song dynasty, aloe was used for curing skin diseases named as 'Nowhae'. As this word was used later in other parts of China, Korea and Japan, it could be assumed that these three countries used imported aloe in the form of dried concentrate for their medical needs. In Korea, the 'DongeuiBogam' written by Joon Hur has the term 'Nowhae' added to its text as well. Aloe was cultivated in the Barbados and Curacao Islands in the Caribbean region by Spain and the Netherlands and was sold commercially to various parts of Europe during the 17th century. Since its first recording in pharmacopeia in Germany during the 12th century, aloe has been listed as a laxative in pharmacopeia in 20 countries. Afterwards, following detailed research on the qualities and effectiveness of aloe, it has been used for a wide variety of medical purposes (Young In and Hyung, 2006).

\section{Aloe Vera as a Functional Food}

Functional foods are defined as foods that are consumed as part of a usual diet but have physiological effect and/or reduce the risk of chronic disease beyond basic nutritional functions. Reports show that Aloe Vera (Barbadensis Miller) gel (AG) contains nutrients and functional activities such as decreasing hyperglycemia. It also reported that a polyphenol extract from Aloe Vera gel decreased glucose levels in induced insulin resistance in mice. (Cardenas-Ibarra et al., 2019).

\section{Heat-treated Dried Powder from Aloe Vera}

The reason why extracts from Aloe are used in a form of heat-treated dried powder for medical purposes is because its high water content later causes putrefaction. Before the development of technology for its processing and manufacturing, the only way to produce Aloe was presumably the traditional heat dry method. For medical purposes Aloe has been used as a laxative, a tonic medicine, or a peptic. Anthraquinones such as aloin and barbaloin are known to be major components (Table 1) (Young In and Hyung, 2006).

Table 2. Aloes for medical uses (Young In and Hyung, 2006)

\begin{tabular}{lccc}
\hline Pharmacopeia & Species & Usage & $\begin{array}{c}\text { Major } \\
\text { component }\end{array}$ \\
\hline & Aloe ferox & & \\
& Miller, Aloe & & \\
& Africana & & \\
JP, BP, EP, etc. & Miller, Aloe & Laxative & Anthraquinones \\
& spicata & & \\
& Baker and & & \\
& their & & \\
& hybrids & & \\
& Aloe & & \\
USP & barbadensis & Laxative & Anthraquinones \\
& Miller (Aloe & & \\
\hline & vera) & & \\
\hline
\end{tabular}

\section{The Use of Aloe for Food and Cosmetic Purposes}

Aloe Vera gel extracts began to be used for health foods / beverages and moisturizing cosmetics, starting in the United States and parts of Europe, during the 1970s. Aloe Vera was especially cultivated and supplied in mass in the United States from its vast farming lands and automated farming methods. Aloe was later produced in the forms of gel extract and powder in order to increase its value as a product in the commercial market, contributing to increased consumption and demand for aloe. The leaves of Aloe Vera are thick and full of pulpy substances compared to other aloe species. The "Aloe Vera gel solution" is a pulpy substance containing polysaccharides which is made of inner gel without the outer layer of leaves and contains almost no anthraquinones. This solution is also produced in powder form as "Aloe Vera gel powder". This powder is originally used only as a vehicle or a diluent in medicines, and as a skin moisturing agent for creams, lotions, soaps, conditioners and shampoos, whereas the yellow sap containing anthraquinones mostly between the outer layer and the gel layer was used in medical purposes. The development of Aloe as a raw material for health food is based on safety rather than pharmacological activity so 


\section{Black Sea Journal of Agriculture}

that aloe has been processed to eliminate anthraquinones which show an alleviation activity for constipation. The gel contains mainly macromolecules such as cellulose, polysaccharides and glycoproteins. The pattern of food consumption has been changing with increased intake of animal proteins and fats rather than plant celluloses. In the light of this, Aloe serves as a good low calorie supplement for providing celluloses, improving fatness, and lowering cholesterol levels. Moreover, Aloe Vera gel extracts have also been used for mucosal regeneration of the stomach and intestine and for skin care. Other species of Aloe that were expanded for use in health food purposes include Aloe Arborescens Miller and Aloe Saponaria Miller, but their leaves are thinner and contain much less gel. This lead to the use of whole leaves, but their use remains very limited due to concerns over the amount of gel and the side effects of anthraquinones. However, it has been known that Aloe saponaria contains no anthraquinones. Three species of Aloe, Aloe vera, Aloe arborescens and Aloe saponaria, are currently listed in the Food Code and Food Supplement Code of Korea and Japan (Table 3) (Young In and Hyung, 2006).

The German Commission E approves the use of aloe for the limited (1-2 weeks) treatment of constipation. The US Food and Drug Administration (FDA) does not permit the use of aloe products as nonprescription drugs for treatment of constipation because of the lack of documented efficacy and safety. Aloe products are controlled as dietary supplements in the United States (Barceloux, 2008).

Table 3. Aloes used for health food and cosmetics (Young In and Hyung, 2006)

\begin{tabular}{|c|c|c|}
\hline Species & $\begin{array}{c}\text { Major } \\
\text { component }\end{array}$ & Usage \\
\hline $\begin{array}{l}\text { Aloe } \\
\text { barbadensis } \\
\text { Miller (Aloe } \\
\text { vera) }\end{array}$ & $\begin{array}{c}\text { Gel extract, } \\
\text { polysaccharides, } \\
\text { glycoproteins } \\
\text { and saponins } \\
\text { Processed whole }\end{array}$ & $\begin{array}{l}\text { Raw material for } \\
\text { functional foods } \\
\text { and cosmetics }\end{array}$ \\
\hline $\begin{array}{l}\text { Aloe } \\
\text { aborescens } \\
\text { Miller }\end{array}$ & $\begin{array}{c}\text { leaves, } \\
\text { anthraquinones } \\
\text { and } \\
\text { polysaccharides }\end{array}$ & $\begin{array}{c}\text { Health food, } \\
\text { peptic and } \\
\text { laxative }\end{array}$ \\
\hline $\begin{array}{l}\text { Aloe saponaria } \\
\text { Miller }\end{array}$ & $\begin{array}{l}\text { Processed whole } \\
\text { leaves, } \\
\text { polysaccharides } \\
\text { and } \\
\text { glycoproteins }\end{array}$ & $\begin{array}{l}\text { Raw material for } \\
\text { functional foods } \\
\text { and cosmetics }\end{array}$ \\
\hline
\end{tabular}

\section{Various Utilizations and Compounds of Aloe Vera}

Aloe Vera is an herbaceous and perennial plant with long thick fleshy leaves that belongs to the Liliaceae family and is similar to cactus in appearance. So far, 75 known compounds are found in Aloe Vera which contains 20 minerals, 20 amino acids, vitamins and water. Among them copper, iron, calcium, zinc, manganese, sodium, potassium, salicylic acid, vitamins A, B, C, E, B12 and folic acid can be pointed out. In vitro studies and in studies that have been conducted on living organisms it has been shown that Aloe Vera inhibits thromboxane (an inhibitor of wound healing), helps healing and reduces inflammation. Magnesium lactate in Aloe Vera gel prevents the reaction of histamine, which causes itching and irritation to skin. It also enhances the immune system activity and synthesis of the cytokine. By inhibition of IL-6 and IL-8 Aloe Vera reduces the adhesion of leukocytes, increases the levels of IL-10 and decreases the levels of TNF alpha, so it is effective in inhibiting inflammatory reactions. Its regenerative property is related to a compound called Glucomannan which is rich in polysaccharides such as mannose that effects on receptors of the fibroblast growth factor and stimulates its activity and proliferation and increases collagen production (Hekmatpou et al., 2018).

It contains 75 potentially active constituents, including polysaccharides, anthraquinone, lectin, superoxide dismutase, glycoprotein, vitamins $\mathrm{C}$ and $\mathrm{E}$, salicylic acids and amino acids. Traditionally, Aloe Vera has been used topically in cosmetic products and herbal remedies in treatment of a range of inflammatory skin diseases for its anti-inflammatory, analgesic, wound healing, scavenging free radicals, antiproliferative, anticarcinogenic and antiaging properties. It is believed that Aloe Vera exerts its anti-inflammatory effects through suppression of cyclooxygenase-2. It has also been used successfully for thermal burns, traumatic surgical wounds, radiationinduced dermatitis and skin ulceration. Although the mechanism of action by which Aloe Vera might facilitate healing is not clearly delineated, one hypothesis is that it exerts its effects as a result of antioxidant and immunomodulatory properties, and cyclooxygenase-2 suppression. One of active compounds in Aloe is salicylic acid, which can be converted into salicylate and thereby inhibits prostaglandin synthesis and the resulting inflammation (Sahebnasagh et al., 2020).

Aloe Vera leaves contain anthraquinones, saccharides, vitamins, amino acids, minerals, enzymes, fatty acids, other emollient, healing, clotting, moisturizing, antiallergic, disinfectant, anti-inflammatory, astringent, choleretic, laxative, and other compounds. Currently, the two most important components of Aloe Vera leaves (latex and pulp) are studied in several research centers worldwide as regards their use by different ethnic groups and to determine the mechanisms of action of the compounds contained within them. Latex, which is yellow and has an unpleasant odor, is also called leaf exudate, bitter sap, blood, or juice and is rich in phenolic compounds - mainly chromones, anthraquinones, and anthrones with particular therapeutic effects (ImeryBuiz, 2012). 


\section{Aloe Vera Extract in Patients with Diabetes}

Hypoglycemic properties of Aloe Vera have been reported for years, few human studies have been carried out so far. Most of these studies have been implemented on patients with diabetes while some of such studies suffered from methodological weaknesses. In models of type I diabetes laboratory animals, it is shown that Aloe Vera extract had a similar effect on blood glucose to that of glibenclamide. Even in patients who did not respond to glibenclamide alone, consumption of Aloe Vera extract for 2 weeks could reduce fast blood glucose. Other studies have also shown the effectiveness of Aloe Vera extract on the regulation of blood glucose levels in diabetic animals. Few studies have indicated a rise in blood sugar levels after consumption of Aloe Vera extract which might be related to the use of different parts of the plant (not the gel) or short duration of the intervention ( 2 times a day for 3 days). Use of Aloe Vera extract in pre - diabetic patients can significantly regulate levels of fast blood glucose within four weeks and revert the levels of lipid profile, within eight weeks. It could be an interesting supplement strategy to alleviate impaired serum glucose level and lipid profile (Alinejad-Mofrad et al., 2015).

\section{Aloe Vera Cream}

Three researching articles identified Aloe Vera which is managed into the form of cream. Researching was found using cream of Aloe Vera Oil (AVO cream) toward wounds recovery with results with significant improvement results using pain assessment tools (VAS), AVO cream efficacy statistical test scores increased significantly.

It identified the effect of Aloe Vera cream $0.5 \%$ in chronic anal fissure treatment and it was found that using Aloe Vera cream could reduce pain and accelerate the process of wound healing during chronic anal fissure treatment. It also identified the using of Aloe Vera cream into reduce pain and accelerate the process of post-surgery wound healing, post defection (hemorrhoidectomy) and found that Aloe Vera cream significantly reduced post-surgery pain at 12, 24, 48 hours and 2 weeks post-surgery and patients who is receiving Aloe Vera cream has decreased when take number two significantly at 24 and 48 hours after hemorrhoidectomy and Aloe Vera cream significantly helps wound healing to post surgery patient during 2 weeks (Rozani and Kusbaryanto, 2019).

In other clinical studies, topical Aloe Vera was compared to silver sulfadiazine or Vaseline gauze in treating burn wound. The average time of healing reduced significantly in Aloe group. Aloe Vera cream has been also applied post-hemorrhoidectomy for ameliorating pain and recovering epithelial in order to accelerate wound healing. Seborrheic dermatitis is an inflammatory skin disorder with high prevalence. Aloe Vera extract has been shown to be effective in this dermal condition, too. Aloe extracts has proven antioxidant activity which protects against ROS-induced membrane and cellular damage (Sahebnasagh et al., 2020).

\section{Aloe Vera Juice and Gel}

A colorless mucilaginous material (gel) is stored within the leaf (hydroparenchyma, pulp, or glass) that contains glycoproteins, lectins, and large quantities of polysaccharides, including acemannan (rich in mannose)-one of the most important for the food, cosmetics, and drug industries (Imery-Buiz, 2012).

Aloe Vera gel is a constituent of food and drink, an antiinflammatory in cosmetics and topical agents, and a moisturizer in lotions. Although experimental studies and anecdotal case reports suggest a wide range of medical applications for Aloe Vera gel, the clinical effectiveness of the oral or topical application of this substance remains unsubstantiated. The dried latex form of Aloe is an approved oral agent based on the cathartic actions of Aloe - emodins and other anthraquinone compounds. The plant portion most commonly used by the pharmaceutical industry is the latex, which stains clothes and fixtures purple (Barceloux, 2008).

All the results of researching prove that Aloe Vera is very useful for used to wound healing process. Aloe Vera gel topical using is done by application it to skiing as medicine for skin conditions such as burns, psoriasis, wound and can be taken orally (through mouth) for conditions including osteoarthritis, intestinal disease, fever. Pharmacological action of this get has assessed through in vitro and in vivo experiments. Preclinical researching results provide evidence that Aloe Vera has activity as anti-inflammatory, antirheumatic, antibacterial, and hypoglycemic. Health benefits Aloe Vera include the application in wound healing process, treat burns and given to protection against skin damage from Aloe Vera is a plan that can produce X-rays. Aloe Vera barbadensis gel combined and tongue protector it was found that using of Aloe Vera gel and tongue protector can reduce duration of wound healing to burning mouth syndrome patients. Others researching that reduce pain score and wound size but also accelerates the healing of alpthous stomatitis wound (Rozani and Kusbaryanto, 2019).

Aloe Vera gel not only increases the amount of collagen in wounds, but also changes the composition of collagen by increasing the collagen crosslinking and thereby accelerates healing of the wound. Studies show that since $99 \%$ of Aloe Vera gel is water, it can increase the flexibility of skin and reduce its fragility. Also, the mucopolysaccharides along with amino acids and zinc in Aloe Vera help skin integrity, retain its moisture, reduce erythema and help prevent skin ulcers. Many studies have shown that using Aloe Vera to treat various wounds such as psoriasis, mouth ulcers, diabetic ulcers herpes and bed sores has had positive effects. Given that the care of pressure ulcers is one of the important and challenging issues in medicine and nursing and prevention of ulcers is one of the main tasks of nurses which is also cost- 


\section{Black Sea Journal of Agriculture}

effective, on the other hand, the use of traditional medicine and herbal plants is one of the ways to prevent PUs and Aloe Vera has positive effects and benefits on the skin (Hekmatpou et al., 2018).

In one study, the use of oral administration of Aloe Vera leaf gel extract for 21 days improved glycoprotein metabolism in diabetic animal models. There is also evidence which shows that the glucose metabolism can be regulated with Aloe Vera. The plant has other properties such as the reduction of hepatic tissue damage resulting from diabetic complications in rats and reduction of the oxidative damage in the hippocampus and cerebral cortex of mice with type 2 diabetes (Alinejad-Mofrad et al., 2015).

One researching has been identified combination of Aloe Vera juice and gel in oral symptomatic lichen planus treatment, the said by combining treatment juice and gel in symptomatic oral lichen planus treatment reduce the duration of pain (Rozani and Kusbaryanto, 2019).

Aloe Vera gel is applied externally to treat skin irritation (such as from insect bites), burns, psoriasis, wounds, radiation dermatitis and frost-bite. It is also frequently found in cosmetic preparations, usually at low doses. Internally, aloe 'juice' is taken as a general tonic to enhance the immune system and to treat constipation. Aloe has also reported antidiabetic, anticancer and antibiotic properties. Aloe plants also yield a resinous exudate known as 'aloes' or 'bitter aloes', which is rich in anthraquinones and a strong laxative. These preparations are no longer recommended due to their potential genotoxic and mutagenic effects. External use of Aloe Vera gel appears to be safe, but there is limited data available on its safety for internal use. Large doses and long-term use should be avoided due to risk of nephritis (kidney inflammation), and studies in mice and rats have indicated genotoxicity and carcinogenicity. Aloe has been demonstrated to lower blood glucose and lipid levels in diabetic patients with hyperlipidemia and patients with metabolic syndrome (Edwards et al., 2015).

\section{Aloe Vera in Prevention of Acute Radiation-Induced Proctitis (ARP)}

In an experimental study, Aloe Vera did not alter the erythema or vasodilation produced by UVB radiation up to 24 hours after exposure. Clinical trials did not demonstrate the efficacy of Aloe Vera gel for the treatment of radiation burns or aphthous stomatitis (Barceloux, 2008).

Aloe Vera ointment was superior to placebo in prevention of acute radiation-induced proctitis (ARP) in patients during radiotherapy (RT). It prevented the symptoms of radiation- induced proctitis, especially diarrhea, hemorrhage, and fecal urgency. Aloe Vera also decreases the burden of systemic inflammation and enhanced quality of life of patients without causing significant adverse event. The results of this study are so promising, suggesting the use of this natural product for prevention of ARP in patients undergoing RT. In addition, this medicinal herb has been successfully used in treatment and alleviating acute radiation-induced proctitis (ARP) symptoms in patients receiving radiotherapy (RT). Aloe Vera mouthwash has shown promised efficacy in prevention and alleviation of radiationinduced mucositits in head and neck cancers without marked side effects. In previous clinical studies, a significant number of patients with chronic radiation proctitis seemed to benefit from combination antioxidant therapy of Vitamin C and E with sustained improvement in their clinical symptoms for as long as 1 year (Sahebnasagh et al., 2020).

\section{Aloe Vera Solution to Stomatitis and Pain Intensity}

Mansouri et al. (2016) using Aloe Vera solution to stomatitis and pain intensity in patient who undergoing chemotherapy procedures and the results were obtained that using of Aloe Vera solution to reduce the pain of chemotherapy to stomatitis patients are very effective with statistical test results on third day (on the 3rd day) 14th day $\mathrm{P}=0.001$ (stomatitis intensity) and $\mathrm{P}=0.001$ (pain intensity).

Pain is common symptoms of many medical problems, which indicates tissue damage. Pain has several types such as acute pain, chronic pain, migraine, musculoskeletal, post-surgery pain, neuropathic pain, etc. One of causes of pain is wound caused by various health problems. Most researching literature reviews that discuss the using of Aloe Vera therapy through skin. Skin is one of organs as a protector which has function as a receiver regulate humidity, temperature modulation. It identify ways to speed the wound healing process and reduce intensity of paint from various health problems with treatment using Aloe Vera. But we can the type or form of Aloe Vera which given in the treatment is gel, cream, solution, juice and oil which given through skin. Only one researching investigates treatment with using Aloe Vera in a type of solution in stomatitis done by gargling. Whereas it is known that one of the most effective absorption of drugs through skin is solution and liquid. Aloe Vera functional to speed up the healing process of wounds into reduce the intensity of pain in the treatment of oral lichen planus, stomatitis, diabetes mellitus, pressure ulcers, venous ulcers, chronic anal fissure, heal burns, burning mouth syndrome, aphthous minor, operation post. So that could be said that the content of Aloe Vera has function to speed up the healing process of wounds and could reduce the intensity of pain which is due to several health body problems. Aloe Vera speeds up the healing process of wounds and reduces the intensity of pain which one Aloe Vera gel was encapsulated in liposome was used in the healing melasma process. Because the content Aloe Vera gel has function as a skin pigmentation modifying agent (Rozani and Kusbaryanto, 2019). 


\section{Utilizing Aloe Vera Waste (AVW)}

During the extraction of Aloe Vera gel from leaves of this plant, a substantial proportion of Aloe Vera waste (AVW) is produced. The AVW is a great environmental concern for its disposal; however, it is rich in various bioactive compounds, which could be valorized as an ingredient of feeds in dairy cattle to reduce enteric methane production and consequently carbon footprint of milk production. Aloe Vera waste (AVW), a residue of Aloe Vera gel-producing industry, decreased methane production in vitro. Inclusion of AVW enhanced organic matter and fiber degradability and volatile fatty acid concentration in vitro. Feeding of AVW (20 g/ kg diet) to lactating cows decreased methane production, yield and intensity. Feeding of AVW increased milk production and improve immunity in lactating cows. Feeding of AVW to lactating cows could decrease carbon footprint of milk production.

In a study, revealed milk production increased due to feeding of AVW. In vivo nutrient digestibility and concentrations of fat, protein, and lactose in milk were not affected, but yields of these milk components increased due to AVW feeding. Supplementation of AVW significantly decreased methane production (g/day), methane yield $(\mathrm{g} / \mathrm{kg}$ dry matter intake or $\mathrm{g} / \mathrm{kg}$ digestible organic matter intake), methane intensity $(\mathrm{g} / \mathrm{kg}$ milk production) or methane conversion ratio. Feeding of AVW improved delayed type of hypersensitivity without affecting other blood variables adversely. Also this study demonstrates that feeding of AVW at $20 \mathrm{~g} / \mathrm{kg}$ dry matter intake to dairy cows increased milk production and decreased methane production, which combined decreased methane production per unit of milk production substantially without health effects. Thus, feeding of AVW could be beneficial for sustainable and cleaner milk production decreasing environmental burdens of residue disposal problems and ruminal methane production (Singh et al., 2021).

\section{Botanical and Ecological Features}

Aloe Vera is a perennial herb, without apparent stems (stem less) in plants under 5 years old. In large populations more than 50 years old, there are adult plants with creeping rhizomes almost $40 \mathrm{~cm}$ long and 6$7 \mathrm{~cm}$ in diameter. A small stem can be distinguished in cultivated plants whose leaves have been harvested from the base, leaving an uncovered section of $1.6 \mathrm{~cm}$ per year. In these plants, the stem is wrapped with thin ochrecolored layers, formed from the remains of the dried leaf ligules covering the compact sand-colored internodes. The beige lateral buds are aligned in tight, light brown knots below the ligule. From these the stem meristem generates stolons 6-11 $\mathrm{mm}$ in diameter and of variable length that grow and emerge from the soil in the form of suckers close to the mother plant. The main root may be distinguished by its darker color (brown to coffee), absence of sheaths, and emission of secondary roots of the same color at their base, which become lighter along their length and are yellowish at the apex (Imery-Buiz, 2012).

\section{Drought Conditions and Necessity for Development Greenhouses in Iran}

Information pertaining to a decrease or increase in the amount of rainfall have significant effects on agricultural and municipal water management, especially in arid and semi-arid countries like Iran. Although some climatic parameters have been shown to have a distinct trend globally (a positive trend for temperature, for example), rainfall behavior varies depending on the location. Since rainfall is the most important source of water for all agricultural requirements, information about rainfall trends is valuable to policy makers (Ghahraman and Taghvaeian, 2008).

As a result, precipitation pattern including rain and snow will change. Other facts and projections show, warm and dry regions will become warmer and drier (Masoudi et al., 2018).

Arid and semi-arid zones are very sensitive and vulnerable to the climate change impacts. Vulnerability to climate change and other hazards constitutes a critical set of interactions between society and environment. The central Asia is particularly vulnerable due to physical geography, which dominated by temperate deserts and semi deserts. Aridity is expected to increase across the entire Central Asian region. Temperature increases are projected to be particularly high in summer and fall, accompanied by decreases in precipitation.

I.R of Iran is located in the North Temperate Zone which lies between the latitudes of $25^{\circ} 14^{\prime}$ and $39^{\circ} 42^{\prime} \mathrm{N}$ and the longitudes of $44^{\circ} 10^{\prime}$ and $63^{\circ} 11^{\prime} \mathrm{E}$ with a total area of approximately 1650000 square kilometers. Elevations range from 26 meters below sea level on the shores of the Caspian Sea to 5671 meters above sea level at the pick of the Mt. Damavand. Drought is one of the most critical factors in Iran. About $50 \%$ of Iran can be classified as arid or semi-arid zones. The average precipitation of the country is $245 \mathrm{~mm}$ per year. Climate parameters, particularly precipitation varies significantly in different parts of the country. There is not a good annual rainfall distribution in most regions of Iran. Not only high temperature in southern, central and lowlands of Iran is a limiting factor, but also low temperature in northern, western and highlands is another limiting factor too. As a fact which Iran is located on dry belt of earth and importance of its vegetation cover and forest ecosystems and also limited of adequate research on climate change, consideration of past climate changes and investigation on future climate projection play an important role in development programs. In the South Khorasan Province, a greater portion of land during last decade became warmer than before. This confirmed the overall global warming in the world. Furthermore, those areas showing decreasing in precipitation during the 
time were more widespread compared with those areas without any changes. The results derived from the trends of climate index confirmed this fact that the overall climate of the province became worse because more than $76 \%$ of the lands showed that the region goes to the drier condition. The hazard classification for climate change was used in the research can be used in the other Places. Unfortunately, the results based on this classification indicated that the areas under very severe and severe hazards cover all parts of province showing need more attention to this part of country and doing related remedial measures like current project of carbon sequestration (Masoudi et al., 2018).

According to latest report that published by National Drought Warning and Monitoring Center (NDWMC) in the In year 2020 - 2021 the average amount of rainfall in country determined $127.1 \mathrm{~mm}$ that it means it is very lower (about 50 percent) lower from the long run average precipitation of the country that is $215 \mathrm{~mm}$ per year (National Drought Warning and Monitoring Center, May 2021).

In this regard, development and extension greenhouses in desert regions of Iran has been considered as a critical and important approach by government for improving efficiency and efficacy of water utilization in agricultural sector of the country. Aloe Vera greenhouses in these disadvantaged, isolated and dried regions of Iran namely South Khorasan and Semnan provinces with very bad desert conditions can improve situation of productivity and employment in them.

\section{Aloe Plants and Iranian Traditional Medicine (ITM)}

Iranian Traditional Medicine (ITM) is rich in intact information about plants that have been used to treat various diseases, especially skin disorders. Herbal drugs have been used worldwide in traditional medicine for treatment of various diseases. World plant biodiversity is the best source of herbal medicine and still about 60\%$80 \%$ world population trust on plant based medicines which are being used since the ancient ages as traditional health care system (Jahandideh, 2016).

The diversity of plant species in Iran can be observed due to the variety of weather conditions that might provide the availability of more natural pharmaceutics and poison plants to people throughout the country. Application of plants is a very ancient medicinal treatment. Thousands of plant species grow in Iran with different kinds of pharmaceutical properties. The only species of Aloe Vera that can grow in Iran is A. littoralis baker that is seen in the southern area and islands of the Persian Gulf. Aloe inner gel is the colorless gel consisting primarily of water and polysaccharides, including pectin, cellulose, hemi cellulose, glucomannan, acemannan and mannose derivatives. Acemannan is considered to be the main functional component of Aloe Vera and is composed of a long chain of acetylated mannose. Among the health benefits of Aloe Vera leaves the acceleration of ulcer healing, immune stimulating, antiviral and anticancer effects can be mentioned (Safari et al., 2019).

Aloe (Aloe littoralis) is important clinically and economically. This plant is native in Iran and natural and traditional of proliferation is very slow, in the result, needs of medicinal industry do not prepare. Aloe $(A$. littoralis) can proliferate from micropropagation technique rapidly (Bayani et al., 2019).

\section{Modern Application and \\ Industrialization of Aloe}

Modern application of Aloe in clinical treatment started in the 1930s. After the curing effects of Aloe Vera on skin ulcers caused by X-ray irradiation were first proven by modern scientific methods, many studies have been conducted for the treatment of various skin diseases such as ulcer, inflammation, and burning caused by X-ray irradiation. With the development of nuclear power, the United States government conducted research on the curing capabilities of Aloe Vera on heat and radiation burns in order to introduce its use in the military. In addition the research on Aloe Vera was accelerated in 1952 when a Japanese boat was contaminated by passing through the US Bikini Islands during a hydrogen bomb test. The US government procured medication using Aloe Vera to treat the radiation burns that the sailors suffered from the irradiated dust. After this incident, scientists became interested in research on the ingredients of aloe which expressed those effects other than anthraquinones as a laxative. After aloe ointment was recognized as an OTC medication for healing wounds on the skin by the USFDA in 1959, extensive research on clinical properties was conducted in terms of its pharmacological and treatment effects. Aside from its ability to heal skin wounds, Aloe Vera has also been proven to cure oral infections and diseases related to the gums. In addition, it has also been verified that Aloe Vera can be clinically applied to chronic ulcers on the foot, can stimulate growth of normal human cells by its lectin, and can cure skin burns and even frostbite (Young In and Hyung, 2006).

Based on these findings, the production of Aloe (especially Aloe Vera) has been industrialized over the last 50 years by growing and processing in large quantities for OTC medications, health foods and cosmetics. Accordingly, mass cultivation and processing technologies have also been developed. Many technological improvements have been achieved such as the High Temperature Short Time (HTST) method for hygienic preparation of the gel, technology for the stabilization of the gel concentrate without destroying the effective components, and the improved freeze drying method or spray drying method to preserve the quality of the gel extract as much as possible. As such, aloe as a raw material has been produced massively and made easily available. However, despite this expansion in 


\section{Black Sea Journal of Agriculture}

production and various research papers, the development of more specialized and professional medications has lagged well behind, presumably because the excessive commercial mentality of company leaders. Instead of investment in R\&D for new products based on the spearhead scientific technology, they have been simply relying on improvements of traditional methods to boost productivity in a strictly commercial manner. In this regard, aloe was simply treated as a cure for all injuries and diseases by these company leaders, which led to criticism from scientists and the perception that aloe is a traditional, homemade medicinal ingredient and nothing more. For example, companies advertised that aloe was used as a panacea by King Alexander or Queen Cleopatra, which simply increased the level of distrust for aloe among the potential customers (Young In and Hyung, 2006).

Two substances from Aloe Vera - a clear gel and its yellow latex - are used to manufacture commercial products. Aloe gel typically is used to make topical medications for skin conditions, such as burns, wounds, frostbite, rashes, psoriasis, cold sores, or dry skin. Aloe latex is used individually or manufactured as a product with other ingredients to be ingested for relief of constipation. Aloe latex may be obtained in a dried form called resin or as "aloe dried juice".

There is conflicting evidence regarding whether Aloe Vera is effective as a treatment for wounds or burns. There is some evidence that topical use of aloe products might relieve symptoms of certain skin disorders, such as psoriasis, acne, or rashes.

Aloe Vera gel is used commercially as an ingredient in yogurts, beverages, and some desserts, but at high or prolonged doses, ingesting aloe latex or whole leaf extract can be toxic. Use of topical aloe Vera in small amounts is likely to be safe (Jamshidi et al., 2018).

Aloe Vera may be prepared as a lotion, gel, soap or cosmetics product for use on skin as a topical medication. For people with allergies to Aloe Vera, skin reactions may include contact dermatitis with mild redness and itching, difficulty with breathing, or swelling of the face, lips, tongue, or throat.

\section{Materials and Methods}

Main locations of doing this study were greenhouses of Aloe Vera in two provinces of Iran, namely South Khorasan Province, east of Iran (especially, first rank of doing this study) and Semnan Province, in the north of the country (second rank of doing this study), because of accessibility of them for researcher. Plus above, author also utilized pictures, documents etc. of its open farming in other provinces of Iran (Figure 4).

In Figure 4 map, shows locations of doing this study as A and B. For doing this study utilized qualitative approach with its main tools for gathering information such as participatory observation, maps, scientific articles, pictures, documents (Iranian and foreign scientific magazines and journals, TV and radio programs, Iranian
Bureau of Statistics), discussion with experts, professors and beneficiaries and field research specially in above two provinces.

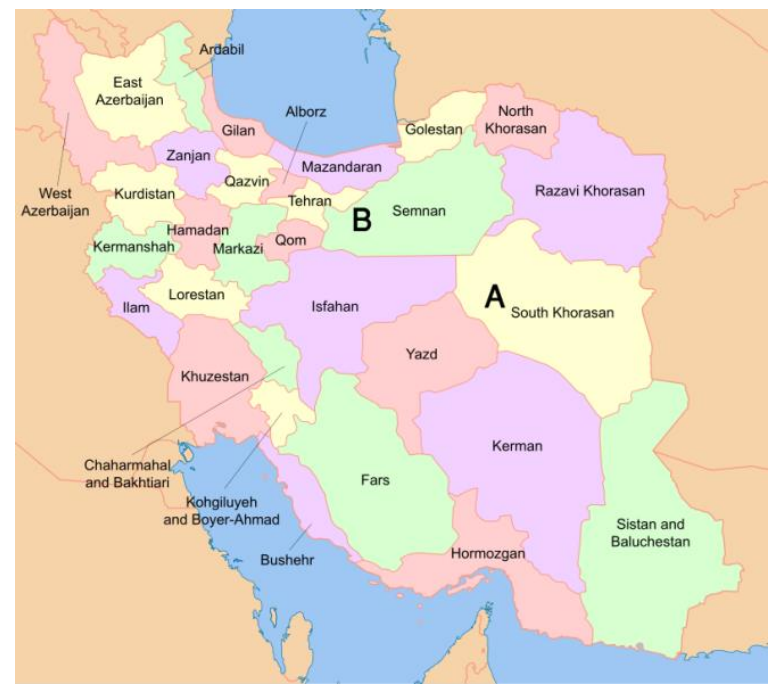

Figure 4. Map locations of doing this study, A (South Khorasan Province, east of Iran) and B (Semnan Province, in the north of the country) (Iranian Bureau of Statistics, 2021).

As Creswell (1994) noted in a qualitative study, one does not begin with a theory to test or verify. Instead consistent with the inductive model of thinking, a theory may emerge during the data collection and analysis phase of the research or be used relatively late in the research process as a basis for comparison with other theories.

South Khorasan Province located in the east of Iran with a total area of 15,030120 ha and mean annual temperature of $17.5^{\circ} \mathrm{C}$ and precipitation of $134 \mathrm{~mm}$, which lies between the latitudes of $30^{\circ} 31^{\prime}$ and $35^{\circ} 05^{\prime} \mathrm{N}$ and the longitudes of $55^{\circ} 22^{\prime}$ and $60^{\circ} 55^{\prime} \mathrm{E}$.

Semnan Province covers an area of 96,816 square kilometers and precipitation of $120 \mathrm{~mm}$, and stretches along the Alborz mountain range and borders to Dasht-e Kavir desert in its southern parts (National Drought Warning and Monitoring Center, May 2021) and (Iranian Bureau of Statistics, 2021).

\section{Results}

In this section of study discussing various aspects, situations and problems of cultivating Aloe Vera greenhouses and their economic importance in South Khorasan and Semnan provinces in east and north of the country. After gathering information following results achieved and classified in cultivating Aloe Vera greenhouses in South Khorasan and Semnan provinces as below:

Aloe Vera is a very resistive plant to dried conditions and water shortages. Its period time for irrigation is one time in each 12-15 days that it is dependent to soil texture and degree of temperature. In spring and summer seasons irrigation occur when the soil dried completely, except 


\section{Black Sea Journal of Agriculture}

this one, irrigation cause decay in the stems of Aloe Vera. Aloe Vera can grow in each types of soil textures but light soils that have drainage are better and preferable for growing of plant. It is better that greenhouse has a proper and light slope of soil for removing ponded water from roots of the plant and also re-usage of this water. Best type of fertilizers for this plant is decayed wastes of animals. Adding coarse materials such as sand cause lightening and alleviating soil texture and improving exchange of air and water for plant. The most ideal type of soil texture for Aloe Vera cultivating is soils with loamy texture.

In the first year of Aloe Vera planting, farmers harvesting its leaves in each four months. But from the second year in each season (three months) its leaves can be harvesting. Amount of harvesting leaves in each time is between 16-22 tons in one ha. Aloe Vera die in under zero degree centigrade and can alive until 55 degree centigrade. Best proper temperature for growing this plant is between 15- 30 degree centigrade. Each leaf of Aloe Vera in time of harvesting has 500 - $1000 \mathrm{~g}$ weight and they must have enough gel for supplying to market. Its amount of gel is dependent to degree of plant maturing and meeting plant nutritional needs. Each shrub can produce 4-6 kg matured leaves and it possible 2-5 times of plant harvesting each year.

High degree of sunlight intensity cause change color of leaves from green to brown. Best quality in production of plant leaves achieve by medium degree of sunlight intensity. Best type for irrigation is tube irrigation, but we can also utilize Crete and drop irrigation types. Plant reproduction of Aloe Vera can be done by seeds, tissue cultures and offshoots (underbrush), but the best type is utilizing offshoots (underbrush) that have life time between 5-8 months and height between 20-25 cm (Figure 5).

Each offshoots Junderbrush) after transferring to destination land will enter to plant recession period for 45 - 90 days and all of their gels will empty and consume for plant. After this time, if meeting plant nutritional needs and preparing good temperature etc. properly, plant can produce leaves with enough and good gels in 9 months later.

The most important problem of greenhouse owners is marketing difficulties for their productions. The prices for Aloe Vera leaves in market are very below and this cause producing of this plant is uneconomical and nonprofit for many of them and some of them bankrupt and exit from production cycle. Also there aren't enough side and processing industries of Aloe Vera in these regions and only one factory of processing Aloe Vera to powder available in Gonabad city in Khorasan Razavi Province with $220 \mathrm{~km}$ distance to Birjand. Its majority of powder production export to foreign especially Russia. These production problems are also confirmed in the whole of the country in: (Lahsaeizadeh, 2007).

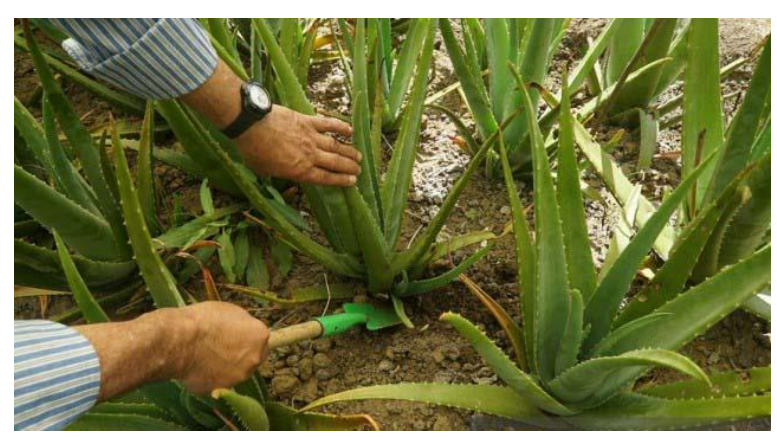

Figure 5. Utilizing offshoots (underbrush) for propagation of Aloe Vera. In a greenhouse with $15 \mathrm{~km}$ distance to Birjand, center of South Khorasan Province, east of Iran (By author; Spring, 2021).

\section{The Situation of the Aloe Vera in the World (Fields Grown, Export and Import)}

There are different statistics from various institutions in these regard that point them as following:

The global Aloe Vera extract market size is projected to reach US\$ 1897.8 million by 2026, from US\$ 1473.4 million in 2020, at a compound annual growth rate (CAGR) of 4.3\% during 2021-2026. (Research Reports, 2020). The global Aloe Vera market is expected to grow at a CAGR of around 7\% during 2021-2026. The global Aloe Vera market was worth US\$ 602 Million in 2019. The global Aloe Vera market is expected to reach US\$ 915 Million by 2025 , growing at a CAGR of $8.60 \%$ during the forecast period (2020-2025).

The utilization of Aloe Vera in the production of personal care products, like face wash, toners, face packs, creams and body lotions, is one of the significant market drivers. With the rising health-consciousness, consumers now prefer products containing natural ingredients, such as Aloe Vera, which are perceived to be safer and healthier than their processed or chemical alternatives. Due to the outbreak of the coronavirus disease (COVID-19), lockdowns have been imposed by governments of numerous countries. This has led to a temporary shutdown of various manufacturing units, thereby negatively influencing the market.

The market has been categorized into concentrates, gels, drinks, powders and capsules. Amongst these, Aloe Vera is mostly consumed in the form of drinks. On the basis of the application, Aloe Vera is mostly used in the cosmetic industry. Other major applications are the pharmaceutical and food industries. The leading market players are Forever Living Products (FLP), Herbalife International of America, Inc., Aloecorp, Aloe Laboratories, Inc., Terry Laboratories, LLC, Lily of the Desert, Foodchem International Corporation, and Pharmachem Laboratories, Inc. (IMARC Group, 2021).

According to IMARC Group, the global Aloe Vera gel market was worth US\$ 465 Million in 2016, growing at a CAGR of around 11\% during 2009-2016. The market has been growing steadily over the last decade driven by varied and increasing usage of Aloe Vera gel in food, 


\section{Black Sea Journal of Agriculture}

health care and cosmetic industries (Reportlinker, 2017). The market has been growing steadily over the last decade driven by varied and increasing usage of Aloe Vera in the food, health care and cosmetic industries. The healthcare and cosmetics sectors are currently the two biggest drivers of Aloe Vera consumption. Region-wise, Thailand was the biggest producer of Aloe Vera accounting for around a third of the total global production. Other leading producers include Mexico, Dominican Republic, United States and Costa Rica.

Aloe Vera has numerous benefits and finds its application in numerous industries such as food, beverages, cosmetics, pharmaceuticals, etc. Numerous studies have also found Aloe Vera to be beneficial in several indications such as teeth and gum problems, constipation, diabetes induced foot ulcers, antimicrobial properties, protection from UV radiation, skin problems, etc. Apart from the current uses, the benefits of Aloe Vera are also being studied in a number of several other indications. This is expected to further diversify the applications of Aloe Vera and create opportunities to launch several new products targeting newer indications. As a result of a rising prevalence of lifestyle related diseases, consumers around the world are becoming more conscious of their health. Driven by this trend, the demand of products containing natural ingredients such as Aloe Vera are being perceived by consumers to be safer and healthier than their processed or chemical alternatives. This coupled by the numerous health benefits of Aloe Vera is expected to create a positive impact on its global demand. Another major factor driving the growth of the Aloe Vera market is its strong consumer acceptance.

Although the demand of Aloe Vera is strong throughout the globe, growth rates in emerging markets such as India, China, Middle East, etc. are expected to be extremely high. Driven by rising economic growth, increasing disposable incomes and low market penetration levels, emerging markets are expected to represent major drivers of future growth. (IMARC Group, 2021). Unfortunately, there aren't precise statistics on extent of farms that cultivating Aloe Vera in the world. In previous, state extent of this in some provinces of Iran.

\section{Discussion and Conclusion}

Aloe Vera is a medicinal plant used since ancient times and cultivated in many warm regions of the world. A large amount of active ingredients and therapeutic properties are known in Aloe Vera however, research for genetic improvement is recent and limited by the form of vegetative propagation. The low genetic variability of Aloe Vera has been overcome with the practice of hybridization assays using species that have high medicinal value. Moreover, the exploitation of polyploidy has played an important role in improving foliar biomass production and tolerance to diseases. The combination of these two breeding strategies has allowed us to explore an important source of genetic variation accumulated by the asexual reproduction of Aloe Vera and donor species, in addition to contributions to the variability that have contributed in each parent recombination and chromosome mutations that occur throughout the formation of sex cells (Imery-Buiz, 2012).

Aloe has been variously used for civilian and traditional medical purposes worldwide for thousands of years, and today it remains in use as a self-medication in western and under-developed countries. As such, aloe's possession of various functions has been clinically proven. It is truly one of the very few plants that are used in such a profusion of applications (Young In and Hyung, 2006).

With polyploidy, hybridization, and even artificial mutations, a lot of experimental genotypes offer a promising future in the field of traditional breeding of Aloe Vera. The application of new technologies has also offered alternative horizons for the improvement of Aloe Vera achieving successful propagation and maintenance of tissues in vitro conditions and the production of transgenic plants via agrobacterium transformation. This background envisions the integration of multidisciplinary groups to achieve significant advances in breeding, cultivation and use of therapeutic benefits of Aloe Vera (Imery-Buiz, 2012).

Following points can be considered as the most important advantages of cultivating Aloe Vera greenhouses in desert regions of Iran plus approaches for their development, extension, processing and marketing:

- This plant doesn't need to rich and fertile soils plus its high degree resistance to salinity of soils and water.

- It has a huge amount of economic advantage for cultivating in small farms and greenhouses with utilizing labor force of family.

- Its cultivating doesn't need to high degree of knowledge in management and agricultural sciences.

- Its water need is very low in comparing to other greenhouses plant such as tomato, cucumber etc. it is estimated its water consumption is 20 percent of tomato, cucumber etc.

- Its high degree resistance to heat and bad air conditions in the limit of 50 degree of centigrade and it has very low need to thermo genic devices and thus its low consumption of fuel and energy in comparing to other productions and thus reducing fuel and energy in large scale in country.

- Its high degree resistance to pests and plant diseases.

- It doesn't need to replant for many years in comparing to other greenhouse productions.

- It needs to very low primary investment for establishing its simple greenhouses plus this important point that its greenhouses don't need to many infrastructures such as asphalt roads, high voltage electricity (three phase electricity), gas 
network optimization, etc.

- Returning primary investment for establishing its greenhouses during less than three years.

- Increasing various utilizations of Aloe Vera in different sectors of society such as health, nutrition (drinks, foods etc.), medicines, cosmetic and toilet etc. industries. This important point must be considered that with very researches that in Iran and world are doing on Aloe Vera, we will see more and more utilizations of this valuable plant in above sectors in future and therefore demand for Aloe Vera will increase in Iran and world in future permanently.

In present, drought and decreasing water resources, land use changes in farms and rural areas, and fragmentation in agricultural lands are most important problems and challenges in agriculture sector of Iran. In this order development greenhouses can be consider as one of the most important solutions in order to confronting to above problems and providing appropriate field for employment in this sector especially for youth people that have academic degrees and graduated in agricultural sector of Iran.

Author during his research with owners of greenhouses found that Aloe Vera can grow in any type of soil with low consumption of water and can adapt with different types of soil and water and thus is a very good option for greenhouses cultivating in desert regions of Iran. Many of agricultural productions have a short, distinguished and limited time for their production and consumption, but their consumption time is very longer and development side and processing industry of agricultural productions can provide conditions and creating positive changes. Processing in these productions allow people consuming them along the year.

Weakness in the field of processing Aloe Vera and development side industry and processing industry of Aloe Vera caused that many farmers avoiding from entering in domain of cultivating this valuable plant. This valuable plant after harvesting in above industries must change and processing to gel, cream, powder, drinking, foods etc. and this important work needs investment by privacy sector and government.

Development side industry and processing industry of Aloe Vera in these regions of Iran can increase amount and value of production, reducing costs and wastes of production, reducing permanent and seasonal unemployment among rural people, providing an appropriate field and context for regional development of agriculture employment opportunities, securing basic needs of local people, connection with other economic sectors, and reducing regional inequality etc.

Because of above, governors and strategic decision makers must be consider development side industry and processing industry of agricultural productions (especially in Aloe Vera) as a key approach for accessing to industrialization strategy of the country and accessing to food security.

\section{Author Contributions}

All task made by single author and the author reviewed and approved the manuscript.

\section{Conflict of Interest}

The author declared that there is no conflict of interest.

\section{References}

Alinejad-Mofrad S, Foadoddini M, Saadatjoo SA, Shayesteh M. 2015. Improvement of glucose and lipid profile status with Aloe vera in pre-diabetic subjects: a randomized controlledtrial. J Diabet Metab Disor, 14: 22. DOI: 10.1186/s40200-0150137-2.

Barceloux DG. 2008. 46 Aloe Vera [Aloe vera (L.) Burm. f. In: part 3 medicinal herbs and essential oils. Medical Toxicology of Natural Substances. John Wiley \& Sons, Inc.., New York, US, pp: 381.

Bayani A, Farahani F, Noormohammadi Z, Nejad Sattari T. 2019. Optimization micropropagation of Aloe (Aloe littoralis) medicinal plant native in Iran (In Persian). URL: http://www.sid.ir (access date: February 05, 2021).

Cardenas-Ibarra L, Villarreal-Perez JZ, Lira-Castillo JC, NavaAleman A. 2017. Randomized double blind crossover trial of Aloe vera, Cnidoscolus chayamansa and placebo for reducing hyperglycemia in women with early metabolic syndrome. Clin Nutri Metab, 14: 1-12.

Creswell JW. 1994. Research design, qualitative \& quantitative approaches. SAGE Publications, London, UK, pp: 304.

Edwards SE, Costa Rocha ID, Williamson EM, Heinrich M. 2015. Aloe vera (Gel) Aloe vera (L.) Burm.f., A. arborescens Mill. and other Aloe spp. In: Phytopharmacy: An evidence-based guide to herbal medicinal products, First Edition. John Wiley \& Sons Ltd., New York, US, pp: 432.

Ghahraman B, Taghvaeian S. 2008. Investigation of annual rainfall trends in Iran. J Agri Sci Technol, 10: 93-97.

Hekmatpou D, Mehrabi F, Rahzani K, Aminiyan A. 2019. The effect of aloe vera clinical trials on prevention and healing of skin wound: A systematic review. IJMS 44(1): 1-9.

Hekmatpou D, Mehrabi F, Rahzani K, Aminiyan A. 2018.The effect of Aloe Vera gel on prevention of pressure ulcers in patients hospitalized in the orthopedic wards: a randomized tripleblind clinical trial. BMC Complem Alter Med, 18: 264 DOI: 10.1186/s12906-018-2326-2.

IMARC Group. 2021. Aloe vera market: global industry trends, share, size, growth, opportunity and forecast 2021-2026. URL: https://www.imarcgroup.com/aloe-vera-gelmanufacturing-plant (access date: February 16, 2021).

Imery-Buiz J. 2012. Genetic resources, chromosome engineering, and crop improvement. Volume 6. CRC Press Taylor \& Francis, New York, US, pp: 884.

Iranian Bureau of Statistics. 2021. Statistical center of Iran URL: https://www.amar.org.ir/ (access date: February 02, 2021).

Jahandideh M, Hajimehdipoor H, Mortazavi SA, Dehpour A, Hassanzadeh G. 2016. A wound healing formulation based on Iranian traditional medicine and its HPTLC fingerprint. Iranian J Pharmac Res, 15: 149-157.

Jamshidi F, Rahimi S, Fadaei Noghani V. 2018. The effect of edible aloe vera gel-persian gum film on Iranian white cheese properties. Iranian J Nutri Sci Food Technol, 74(13): 1.

Lahsaeizadeh A. 2007. Iran sociology of agriculture (In Persian). Samt Publication of Iranian Human Sciences Universities, Tehran, Iran, pp: 154.

Mansouri P, Haghighi M, Beheshti Pour N, Ramzi M. 2016. The 


\section{Black Sea Journal of Agriculture}

effect of aloe vera solution on chemotherapy-induced stomatitis in clients with lymphoma and leukemia: A randomized controlled clinical trial. Int J Commun Based Nurs Midwifery, 4(2): 119-126.

Masoudi M, Yousefi M, Behbahani N. 2018. Hazard assessment of climate changes in south Khorasan province, Iran. EQA Environ Qual, 29: 29-39. DOI: 10.6092/issn.2281-4485/7910.

National Drought Warning and Monitoring Center (NDWMC). 2021. Periodical reports on the average amount of rainfall in Iran. URL: https://ndc.irimo.ir/far (access date: February 12, 2021).

Noori M. 2012. Introducing medical plant of Aloe vera. URL: http://www.sid.ir (access date: January 23, 2021).

Reportlinker. 2017. Aloe Vera Gel Market: Global Industry Trends, Share, Size, Growth, Opportunity and Forecast 20172022. URL: https://www.prnewswire.com/newsreleases/aloe-vera-gel-market-global-industry-trends-sharesize-growth-opportunity-and-forecast-2017-2022300419789.html (access date: February 07, 2021).

Research Reports. 2020. Global Aloe Vera Extract Sales Market Report 2020.

URL:

https://www.360researchreports.com/global-aloe-veraextract-sales-market-16689744 (access date: February 07, 2021).

Rozani M, Kusbaryanto A. 2019. Efficacy aloe vera in treatment:
A literature review. J Complement Med Alt Healthcare, 10(1): 555776.

Safiaghdam H, Oveissi V, Bahramsoltani R, Farzaei MH, Rahimi R. 2017. Effects of aloe vera (l.) burm. f. in gingivitis: a review of clinical trials. Res J Pharmacognosy, 4: 57.

Safari M, Nejad MCD, Mesbah M, Nejad JA. 2019. Effects of aloe vera extract on growth and some hematological parameters of shirbot, Tor grypus (Heckel, 1843). Iranian J Fisher Sci, 18(3): 445-456.

Singh P, Singh Hundal J, Kumar Patra A, Wadhwa M, Sharma A. 2021. Sustainable utilization of Aloe vera waste in the diet of lactating cows for improvement of milk production performance and reduction of carbon footprint. J Cleaner Prod, 288: 125118.

Sahebnasagh A, Ghasemi A, Akbari J, Alipour A, Lashkardoost H, Ala S, Hosseinimehr SJ, Salehifar E. 2020. Prevention of acute radiation-induced proctitis by aloe vera: a prospective randomized, double-blind, placebo controlled clinical trial in Pelvic Cancer patients. BMC Complem Med Therap, 20: 146. DOI: 10.1186/s12906-020-02935-2

Young In P, Hyung JT. 2006. 6. Perspective of industrial application of Aloe Vera. In: New Perspectives on Aloe. URL: https://link.springer.com/book/10.1007/0-387-34636-8 (access date: February 11, 2021). 